REJ - Revista de Estudios de la Justicia - No 1 - Año 2002

\title{
EL RECURSO DE QUEJA EN EL NUEVO PROCEDIMIENTO PENAL
}

Cristián Arias Vicencio*

I. Improcedencia del recurso de queja como medio de impugnación de la sentencia de nulidad o la de reemplazo; II. Fundamentos sistemáticos de la improcedencia del recurso de queja como mecanismo de impugnación de la decisión sobre un recurso de nulidad; III. Una propuesta acerca de la procedencia excepcional del recurso de queja en el nuevo procedimiento penal; IV. Mínimas consideraciones sobre un fallo de la Corte Suprema que acoge un recurso de queja dejando sin efecto una sentencia de nulidad parcialmente absolutoria: a) Omisión de pronunciamiento explícito sobre la naturaleza jurídica de la resolución enmendada; b) Alteración de los hechos fijados en la instancia como constitutivo de falta o abuso grave; c) ¿Hubo alteración de los hechos?; d) Mínimas consideraciones sobre la determinación del límite entre los actos preparatorios y la tentativa; e) Incidencia en las condiciones de independencia personal de los jueces que deberán resolver en forma definitiva la cuestión.

\section{IMPROCEDENCIA DEL RECURSO DE QUEJA COMO MEDIO DE IMPUGNACION DE LA SENTENCIA DE NULIDAD O LA DE REEMPLAZO}

Señalaremos en síntesis los motivos que hacen absolutamente improcedente el recurso de queja, ni aún en forma excepcional, como medio de impugnación de la sentencia de nulidad o la de reemplazo que eventualmente se dicte en el recurso de nulidad:

1. El recurso de queja sólo procede respecto de sentencias definitivas e interlocutorias que ponen término al juicio o hacen imposible su continuación.

Esta norma clara y expresa la encontramos en el artículo 545 del Código Orgánico de Tribunales, en adelante COT.

Respecto a lo que debe entenderse por sentencia definitiva e interlocutoria jamás ha existido controversia alguna en la doctrina nacional ya que estas categorías se encuentran definidas en el artículo 158 del Código de Procedimiento Civil, en adelante CPC.

2. La sentencia de nulidad y la de reemplazo que eventualmente se dicte no son sentencia definitiva ni interlocutoria.

Este supuesto también es inobjetable si se acepta a su turno algo tan básico y evidente como que el recurso de nulidad no es instancia ${ }^{1}$ y que tampoco falla incidente alguno.

\footnotetext{
* Colaborador del Centro de Estudios de la Justicia. Abogado Asesor del Departamento de Estudios de la Defensoría Penal Pública. Profesor de Derecho Procesal de la Universidad La República.
} 
Hasta ahora es doctrina unánime que la sentencia de casación no es susceptible de ser clasificada de conformidad con el artículo 158 del CPC ${ }^{2}$. Tal consenso doctrinario es perfectamente aplicable a la decisión sobre un recurso de nulidad del nuevo sistema procesal penal si se tiene claro que tal recurso no constituye instancia puesto que la única instancia que existe es la que se produce ante el tribunal del juicio oral o ante el juez de garantía en su caso.

El traslado mutatis mutandi de esta conclusión a la actual sentencia de nulidad y de reemplazo no es antojadizo. El nuevo procedimiento no ha innovado en la clasificación de las resoluciones judiciales $\mathrm{y}$, antes bien, ha recogido expresamente la nomenclatura tradicional en el sistema de recursos. En efecto, el artículo 362 del Código Procesal Penal, en adelante CPP, declara que las sentencias interlocutorias, autos y decretos son resoluciones susceptibles del recurso de reposición, recogiendo explícitamente esta nomenclatura. Igualmente se llega a esta conclusión por aplicación de lo dispuesto en el artículo 52 del CPP3.

Si pudiera surgir alguna duda en torno a la sentencia de reemplazo ésta se disipa por la sola consideración que la sentencia sustitutiva es una mera consecuencia de la sentencia que acoge un recurso de nulidad, de tal manera que no ha hecho más que poner fin al recurso de nulidad y no ha puesto término a una instancia que no se ha producido

${ }^{1} \mathrm{El}$ concepto de instancia reconoce también una definición legal y está vinculado indisolublemente al recurso de apelación. El artículo 188 del COT nos enseña que "la competencia de que se halla revestido un tribunal puede ser o para fallar un asunto en una sola instancia, de modo que la sentencia sea inapelable; o para fallarlo en primera instancia, de manera que la sentencia quede sujeta al recurso de apelación". A fortiori se define la segunda instancia como el conocimiento y fallo del recurso de apelación. En ese sentido y no en otro se usa por el legislador el concepto de instancia en el artículo 158 del CPC y además, entre otras, en diversas disposiciones del Título XVIII, del Libro I, del CPC, todas comprendidas en las disposiciones comunes a todo procedimiento.

2 Así es doctrina unánime que la resolución que falla un recurso de casación no es susceptible de ser clasificada de acuerdo con las categorías del artículo 158 del CPC. Así según el profesor Cristián Maturana Miquel "no tiene el carácter de sentencia definitiva aquella que se pronuncia sobre el recurso de casación, puesto que éste no constituye instancia" (Disposiciones comunes a todo procedimiento, Cristián Maturana Miquel, separata. Facultad de Derecho Universidad de Chile. Octubre de 1998). En el mismo sentido Carlos Alberto Stoehrel Maes y Davor Harasic Yaksic: "Sólo es sentencia definitiva la que pone fin a la instancia. Como el tribunal respectivo puede conocer de un asunto en única, primera o segunda instancia, habrá sentencias definitivas de única, primera o segunda instancia. La sentencia que recae en un recurso de casación en el fondo no puede, por esta razón, ser calificada de sentencia definitiva". (De las disposiciones comunes a todo procedimiento y de los incidentes, Quinta Edición, Editorial Jurídica de Chile 1995). Finalmente Mario Casarino Viterbo, en su Manual de Derecho Procesal, en edición revisada tanto por su autor como por el Departamento de Derecho Procesal de la Facultad de Derecho de la Universidad de Chile, bajo la Dirección de Roberto Nahum Anuch, señala que hay resoluciones judiciales "que realmente es imposible encasillar en la clasificación (del articulo 158) por mucho esfuerzo que se gaste; tal es el caso de las que fallan un recurso de casación" y agrega "las sentencias de casación, tanto las que rechazan el recurso cuanto las que lo acogen, no son propiamente hablando sentencias definitivas, a pesar de que participan de sus características formales, porque la casación no es instancia” (Manual de Derecho Procesal, Derecho Procesal Civil, Tomo III, Quinta Edición, Editorial Jurídica de Chile, 1994).

3 Artículo 52. "Aplicación de normas comunes a todo procedimiento. Serán aplicables al procedimiento penal, en cuanto no se opusieren a lo estatuido en este Código o en leyes especiales, las normas comunes a todo procedimiento contempladas en el Libro I del Código de Procedimiento Civil’. El hecho que el artículo 362 recoja la nomenclatura tradicional es prueba que no hay nada que se oponga a la remisión. Pero aún más, si el asunto se trata precisamente de la pretendida aplicación de un recurso regulado "fuera del Código Procesal Penal", resultaría aún más plausible la aplicación directa el 158, sin necesidad de pasar por la norma de remisión del artículo 52, si todavía la disposición común a todo procedimiento contiene una definición legal de sentencia definitiva que, por aplicación del artículo 20 del Código Civil, se debe entender en su significado legal y en ninguno otro. 
por mucho que con su pronunciamiento, obviamente, se ha puesto término al juicio, concepto que rebasa la definición legal de sentencia definitiva.

Todavía más, de conformidad con lo que disponen los artículos 385 y 386 del $\mathrm{CPP}^{4}$, la sentencia de reemplazo que se contempla en el nuevo sistema procesal penal es de carácter absolutamente excepcional y sólo podrá dictarse cuando la causal que prospera es de pura aplicación de derecho. La regla general la establece el artículo 386 que dispone el reenvío imperativamente, a menos que se den los supuestos del artículo 385. Además, en nuestro concepto, aún en las hipótesis del artículo 385 resulta facultativo para el tribunal dictarla pudiendo siempre optar por el reenvío, según resulta de considerar, con la suficiente importancia que tiene, el empleo del vocablo "podrá" escogido por el legislador. Debemos agregar que esta facultad para pronunciar sentencia de reemplazo se encuentra establecida sólo en favor del imputado como se puede concluir de las hipótesis que la hacen procedente, todas las cuales se refieren a una sentencia de juicio que ha resultado gravosa para éste.

De acuerdo con estos tres conceptos -excepcionalidad, discrecionalidad y unilateralidad- bien se puede concluir que la sentencia de reemplazo es así de restrictiva en el nuevo sistema ya que, de otro modo, se podría afectar oblicuamente el derecho al juicio, dado que una decisión final, adoptada por el mismo tribunal que ha anulado el juicio, equivale a resolver el asunto fuera de instancia, fuera de la única que se contempla y que es ante el tribunal de juicio. Esta decisión fuera de instancia es cuestión que al legislador no le agrada, a tal punto que no considera obstáculo para repetir el juicio oral el hecho que el vicio o defecto se haya cometido en el pronunciamiento mismo de la sentencia. Entonces el legislador es capaz de sacrificar el concepto de instancia-conocimiento cabal y sin mediación tanto de los hechos como del derecho- sólo en la medida que ello no perjudique al imputado y por el contrario, a todas luces, lo beneficie.

Concebida la sentencia de reemplazo en estos términos mal podría considerarse ni aún extremando los esfuerzos para hacer calzar su contenido con la definición del artículo 158 del CPC- como una suerte de instancia ficta que se produciría como resultado de la anulación de un juicio. Entonces, la sentencia de reemplazo que se contempla en el recurso de nulidad no puede ni siquiera ser asimilable a la sentencia de instancia ${ }^{5}$.

4 Artículo 385. "Nulidad de la sentencia. La Corte podrá invalidar sólo la sentencia y dictar, sin nueva audiencia pero separadamente, la sentencia de reemplazo que se conformare a la ley, si la causal de nulidad no se refiriere a formalidades del juicio ni a los hechos y circunstancias que se hubieren dado por probados, sino que se debiere a que el fallo hubiere calificado de delito un hecho que la ley no considerare tal, aplicado una pena cuando no procediere aplicar pena alguna, o impuesto una superior a la que legalmente correspondiere.". Artículo 386 Nulidad del juicio oral y de la sentencia. "Salvo los casos mencionados en el artículo 385, si la Corte acogiere el recurso anulará la sentencia y el juicio oral, determinará el estado en que hubiere de quedar el procedimiento y ordenará la remisión de los autos al tribunal no inhabilitado que correspondiere, para que éste disponga la realización de un nuevo juicio oral. No será obstáculo para que se ordene efectuar un nuevo juicio oral la circunstancia de haberse dado lugar al recurso por un vicio o defecto cometido en el pronunciamiento mismo de la sentencia.

5 Nuestro punto de partida se encontraba en la definición legal de instancia (vid nota 1) sin embargo no queríamos agotar allí el análisis ya que, aún no siendo este el caso, al enfrentarnos a un nuevo sistema procesal se hace imprescindible revisar algunos de los criterios tradicionalmente sostenidos en materia procesal. En un procedimiento por actas quizás resulte un delirio esta disquisición sobre el concepto de instancia ya que no es tan diversa la forma de conocimiento del asunto, mediatizada, que tiene tanto el tribunal de primera instancia, cuanto el que conoce del recurso de apelación. En un sistema regido por la oralidad, la inadecuada delimitación del concepto de instancia puede producir una patología, precisamente porque allí donde el asunto se resuelve fuera de instancia se habrá sacrificado el concepto mismo de juicio. Una razón evidente que ha llevado al legislador a no generar un juicio de doble instancia no es tanto su inconveniencia como su 
3. De acuerdo a todo lo dicho ni la sentencia de nulidad ni la sentencia de reemplazo pueden ser consideradas resoluciones susceptibles de ser revisadas por la vía disciplinaria. Así la improcedencia del recurso de queja se deriva por entero de la aplicación lisa y llana de las normas que lo regulan en el COT, en concordancia con el artículo 158 del CPC, regla básica de las disposiciones comunes a todo procedimiento.

Sin embargo no se puede olvidar que, además, el artículo 387 del CPP contiene una enfática declaración en el sentido que la resolución que fallare un recurso de nulidad no será susceptible de recurso alguno, sin perjuicio de la revisión de la sentencia condenatoria firme que, como sabemos, no es recurso. Esta manifiesta prohibición de recurso debería llevar por si misma a descartar la posibilidad de revisión en sede disciplinaria de tan trascendente decisión jurisdiccional ${ }^{6}$.

\section{FUNDAMENTOS SISTEMATICOS DE LA IMPROCEDENCIA DEL RECURSO DE QUEJA COMO MECANISMO DE IMPUGNACION DE LA DECISION SOBRE UN RECURSO DE NULIDAD}

La interpretación sistemática de los recursos contemplados en el nuevo procedimiento penal lleva a la conclusión que el de queja no resulta para nada acorde con un juicio de única instancia, donde los recursos se consideran como medios de impugnación a iniciativa de las partes (intervinientes), especialmente para salvaguarda de las garantías de orden procesal, entre las que se consagra precisamente el derecho al recurso. Así, se ha dejado atrás el sistema recursivo propio de un sistema inquisitivo, en que se producía una revisión jerárquica de las decisiones jurisdiccionales y, por regla general, la revisión de oficio de las decisiones de los inferiores.

Esta revisión de oficio es muy característica del recurso de queja el cual permite, aún habiéndose declarado su inadmisibilidad o improcedencia, la revisión de la decisión impugnada por aplicación de la cláusula contemplada en el artículo 545, inciso primero del COT que reza: "sin perjuicio de la atribución de la Corte Suprema para actuar de oficio en ejercicio de sus facultades disciplinarias", a lo que debe sumarse la amplísima competencia que se otorga al revisor disciplinario para adoptar "las medidas conducentes"

difícil implementación. Una auténtica segunda instancia, en un procedimiento oral, significaría la reproducción completa de un juicio ante el tribunal superior. Tal reproducción sería insustituible por una revisión de actas en segunda instancia, que tornaría en inútil todo lo actuado en la primera instancia oral.

${ }^{6} \mathrm{Si}$ bien en el trámite legislativo se incluyó con bastante mutismo el artículo 387 -incorporado en el Senadosin duda su interpretación debe conciliarse con toda la discusión parlamentaria, de la cual se desprende que se pretendió dar al recurso de nulidad un sesgo restrictivo de la revisión de lo decidido en instancia, estimándose "conveniente establecer, como regla general, que la revisión de los fallos de los tribunales de juicio oral en lo penal ( $\mathrm{y}$ de los jueces de garantía, cuando resuelvan los asuntos sometidos al procedimiento simplificado o al procedimiento abreviado) quede radicada en las Cortes de Apelaciones. Esto es explicable sobre todo si se piensa que las sentencias que examinarán provenientes de los tribunales de juicio oral habrán sido dictadas por tres jueces de Derecho, al término de un juicio público rodeado de garantías para todas las partes, lo cual debería reducir significativamente las posibilidades de error o incorrección" (Emilio Pfeffer Urquiaga, Código Procesal Penal anotado y concordado, Ed. Jurídica, pág. 369 y ss). Estos objetivos obviamente se distorsionan si se permite la revisión por vía de queja que consiste precisamente en un control disciplinario y jerárquico de las actuaciones del inferior, incluidas las actuaciones propiamente jurisdiccionales. 
a poner remedio a la falta o abuso, entre las que se puede contar la "invalidación de una resolución jurisdiccional’”.

Como bien lo resalta Alex Carocca, al hacer una revisión crítica del sistema tradicional de recursos, algunos de los rasgos más salientes del antiguo sistema son: la hipertrofia del sistema de impugnación por la vía de los recursos, la consideración jerarquizada de los mismos y la revisión de oficio de las más importantes resoluciones judiciales ${ }^{8}$.

En definitiva la aceptación del recurso de queja como medio de impugnación de la sentencia de nulidad genera, en los hechos, una suerte de instancia múltiple no autorizada por el nuevo sistema procesal penal o bien un sistema de nulidad con revisión jerárquica igualmente extraño al sistema de nulidad 9 .

De tolerarse la revisión disciplinaria de la sentencia de nulidad, cada vez que el tribunal llamado a conocerla sea una Corte de Apelaciones, existirá la posibilidad de revisión por parte de la Corte Suprema ${ }^{10}$. Así las cosas podría sostenerse que esta praxis

${ }^{7}$ El profesor Raúl Tavolari sostiene que en el conocimiento y fallo del recurso de queja resulta improcedente modificar resoluciones jurisdiccionales salvo que sean dictadas por árbitros arbitradores. Aún adhiriendo a esta interpretación resulta evidente que la praxis de la Corte Suprema ha hecho uso no mezquino de esta facultad y, como bien lo destaca este autor, "aún cuando no aporte elementos de análisis ni de razonamientos jurídicos ni lógicos, por la enorme fuerza que le otorga el constituir un hábito enraizado en jueces y abogados, esta circunstancia de la práctica habitual, constituye sin dudas, un poderoso refuerzo a la opinión a favor de estimar facultado, al tribunal que acoge un recurso de queja, para modificar el contenido de la resolución". Una opinión intermedia, descrita por el mismo profesor, se basa precisamente en las facultades del tribunal revisor para actuar de oficio, con idénticos resultados prácticos que si se sostuviera la opinión positiva $y$, agreguemos, de resultados incalculables, ya que las facultades de oficio obviamente escapan incluso a las pretensiones recursivas de las partes (Raúl Tavolari Oliveros, Recursos de Casación y Queja, Nuevo régimen, Editorial Jurídica Conosur Ltda.. 1996, pág 27 y ss).

8 Así este autor expresa que "tan profundamente arraigada se encontraba esta concepción, que transcurridos casi dos siglos desde la independencia nacional y establecido un régimen político de tipo republicano, de todos modos se sigue considerando a los tribunales como un cuerpo de funcionarios administrativos, que mantiene entre sí relaciones de estricta jerarquía, dando origen a la denominada pirámide judicial, a cuya cabeza en lugar del Soberano se sitúa ahora la Corte Suprema, con poderes incontrarrestables al interior del sistema" y, agrega, a propósito de la multiplicidad de instancia, que "una manifestación extrema de la verticalidad en el ejercicio de la jurisdicción concebida como una administración, y en contra del concepto de un recurso propiamente tal, se contempla la revisión de las más importantes resoluciones judiciales, de oficio, vale decir, sin mediar petición de la parte agraviada, por medio de la añeja e hispánica forma de la consulta, que a estas alturas no puede sino ser calificada de un verdadero fósil jurídico" (Nuevo Proceso Penal, AAVV, Editorial Jurídica Cono Sur Ltda.. Recursos en el nuevo sistema procesal penal. pág. 300 y ss.)

${ }^{9} \mathrm{La}$ crítica de la instancia múltiple, como efecto práctico inaceptable del recurso de queja, obviamente es muy anterior a la consagración normativa del nuevo sistema procesal penal y es realzado por la propia Corte Suprema en informe de 23 de Abril de 1993, remitido al Senado durante la tramitación del proyecto de la Ley $\mathrm{N}^{\circ} 19.374$ que modificó sustancialmente el régimen de los recursos de queja y casación. En ese informe la mutilación del recurso de queja es celebrada por "el espíritu que anima el proyecto, en cuanto por las modificaciones de esos preceptos se persigue restringir drásticamente la procedencia del recurso de queja, dado que en razón de su estructura actual es interpuesta indiscriminadamente respecto de cualquier resolución, aun cuando existan o procedan en contra de ellas los demás recursos ordinarios o extraordinarios establecidos expresamente en el ordenamiento para ese fin" y, agrega, "tal situación ha venido a desbordar la labor jurisdiccional de los Tribunales Superiores, particularmente de esta Corte, por cuanto ha generado una verdadera tercera instancia, postergando la vigencia del recurso de casación de fondo, cuyo conocimiento por su naturaleza y finalidad es de la esencia de la función más propia de este tribunal, como cautelador de la recta y genuina aplicación de la ley".

${ }^{10}$ Esta posibilidad de revisión, como es obvio, resulta imposible si ha sido la Corte Suprema la que ha fallado el recurso de nulidad, pero se torna paradójica si ha sido una Corte de Apelaciones la que ha fallado el 
facilita una herética resurrección del trámite de la consulta permitiendo que el perdidoso, alzándose por esta vía, logre convencer al superior jerárquico que la decisión del inferior es incorrecta y, aún siendo improcedente en lo procesal formal tal revisión, el superior, actuando de oficio, podría enmendar lo resuelto tanto en lo relativo a la pura aplicación del derecho cuanto a la fijación de los hechos.

$\mathrm{Al}$ postular que el recurso de queja quede excluido por completo, como una forma de enmendar lo resuelto en sede de nulidad, no se hace más que reafirmar la distribución de competencias que entre la Corte Suprema y las Cortes de Apelaciones realizó conscientemente el legislador, tal como quedó establecido en la historia fidedigna del establecimiento del recurso de nulidad. Dicho de otra manera, es esperable que el diseño normativo de la distribución de competencia jurisdiccional penal, no se vea modificado, de hecho, por aplicación de competencia disciplinaria.

Así en el Senado se estimó "que las controversias de fondo en cuanto a la aplicación de la ley penal, con toda la trascendencia que tienen, es una materia que las Cortes de Apelaciones están, o deberian estar, perfectamente capacitadas para dirimir" y sólo "por razones de economia procesal, se optó por radicar en la Corte Suprema el conocimiento de los recursos fundados en distintas causales, cuando correspondiere pronunciarse sobre algunas a la Corte de Apelaciones y sobre otras a la Corte Suprema". Todavía más, en lo que dice relación con la revisión de la fijación normada de los hechos, se optó por entregarla por completo a las Cortes de Apelaciones ya que, como se señaló, "es preciso observar que uno de los motivos absolutos de nulidad consiste en que la sentencia bubiere omitido alguno de los contenidos que necesariamente debe figurar en ella, entre los cuales se cuenta la valoración de los medios de prueba que fundamentaren las conclusiones acerca de los hechos y circunstancias que se dieren por probados", recogiendo de esta manera "la inquietud que tuvo la Cámara de Diputados al crear el recurso extraordinario, pero con mayor propiedad"11

Más expresivo aún resulta lo que el Senado entendió como una derivación del propósito de acercar la administración de la justicia penal al ciudadano común, asumido como uno de los grandes objetivos de la reforma procesal penal, al adoptar, en consecuencia, "como criterio básico radicar el conocimiento del recurso que se pueda deducir contra la sentencia del tribunal de juicio oral en la respectiva Corte de Apelaciones. Como explicamos a continuación, reservamos también ciertas circunstancias que permiten acudir ante la Corte Suprema, pero en forma directa, y no adicional al conocimiento del recurso por la Corte de Apelaciones. Pensamos que, si se pudiera recurrir ante la Corte Suprema por el fallo que su vez dicte la Corte de Apelaciones, se daría una solución inconveniente, que dilataría el término del proceso penal, restando trascendencia a la decisión del tribunal de juicio oral, ante el cual se ha desarrollado todo el proceso; perjudicaria la percepción de las personas acerca de la oportunidad de la justicia, al alejar la resolución definitiva del caso de la fecha en que ocurrieron los hechos, y obligaría a todas las partes a llegar a Santiago, haciéndolas incurrir en mayores desembolsos o, en su caso, recargando la labor de la defensoría penal pública, por la sola decisión que pueda tomar una de ellas"'2.

Entonces, la subsistencia del recurso de queja genera un efecto que el legislador claramente rechazó en el diseño normativo de los recursos: la acumulación de toda la competencia anulatoria radicada en la Corte Suprema. De esta manera la Corte Suprema, en los hechos, pasaría a detentar competencia para conocer de todas las causales de

recurso, luego que la Corte Suprema ha hecho uso de la facultad de declinar su conocimiento, remitiéndolo a la Corte de Apelaciones respectiva, en las hipótesis que regula el artículo 383 del CPP.

${ }^{11}$ Emilio Pfeffer Urquiaga, Código Procesal Penal anotado y concordado, Ed. Jurídica, pág. 369 y ss.

12 Sabas Chahuán Sarrás, Manual del Nuevo Procedimiento Penal, Conosur, 2001, pág. 338. 
nulidad en circunstancias que claramente se le quiso entregar el conocimiento de las que se estimaron más graves: las que constituyan una infracción de garantías constitucionales. También conoce de las controversias sobre la correcta aplicación del derecho en tanto existan interpretaciones jurídicas diversas asunto que, por cierto, también persigue dar plena aplicación a una garantía: la igualdad ante la ley. Finalmente, conoce también de causales que no le son propias, tan sólo por razones de economía procesalt ${ }^{33}$ al, cuando resulta necesario evitar un doble pronunciamiento ${ }^{14}$.

Por otra parte, se puede identificar otra inconsistencia del recurso de queja injertado en el nuevo sistema procesal, que dice relación sus decisiones posibles. Así, la Corte Suprema podría decidir derechamente el conflicto sin sujeción a las peticiones de las partes. Podría anular el juicio o la sentencia y en este último evento bien podría disponer una nueva vista del recurso o el pronunciamiento de una sentencia por tribunal no inhabilitado o bien fallar ella misma el conflicto, sin reenviar el asunto a la instancia o al tribunal llamado a conocer del recurso de nulidad.

Como se puede ver las decisiones posibles son infinitas, a menos que el tribunal autolimite sus potestades, precisamente por aplicación de las normas generales sobre los recursos que contempla el CPP, especialmente el artículo 360, inciso primero, que prohíbe la extra petita y la reformatio in peius. La aplicación de este precepto es sensatamente exigible a cualquier recurso que verse sobre materias penales, aún cuando no se encuentre disciplinado específicamente en el Código del ramo. El problema surge precisamente porque el recurso de queja, aún declarado inadmisible o rechazado autorizaría para actuar de oficio, es decir, más allá del recurso propiamente tal, generándose el peligro de esta suerte de resurrección de la consulta y la infracción de las prohibiciones de ultra petita y de reformatio in peius.

Otra consideración sobre la desnaturalización del sistema de recursos, por obra de la impugnación disciplinaria, es la posibilidad de revisión de lo resuelto una y otra vez, generando lo que Julio Maier denomina el regressus in infinitum ${ }^{15}$. Esto significa que si el superior jerárquico ordenara un nuevo juicio o una nueva vista y fallo del recurso de nulidad, ante una segunda decisión adversa, renacería la posibilidad del quejoso de alzarse nuevamente por la vía disciplinaria.

Esta última idea no puede ser concebida como una mera hipótesis de laboratorio ya que la praxis forense es lo suficientemente imaginativa como para darnos por librados. Lo que resulta extraordinariamente grave es que este eterno regreso podría -aunque no deberíaoperar en perjuicio de la inmutabilidad de la segunda decisión absolutoria. Esto significa lo siguiente: si es anulado un juicio y la segunda sentencia resulta absolutoria, esta última decisión no es susceptible de recurso alguno, por disposición del inciso segundo del artículo 387. En estricto rigor tampoco lo es la segunda decisión condenatoria que es precedida de una decisión también condenatoria que ha sido declarada ineficaz.

\footnotetext{
13 Ib. Idem nota 11

14 Desde luego insinuamos la existencia de un nuevo rol de la Corte Suprema en el sistema procesal penal, que dice relación con su avocación casi exclusiva a preservar las garantías de los individuos, asunto cuya demostración corresponde a un análisis sistemático del recurso de nulidad, cuestión que escapa en parte al contenido de este comentario.

15 Julio Maier, Derecho Procesal Penal Argentino, Hamurabi, Buenos Aires, 1989, pág 714.
} 
En lo que nos interesa, la inmutabilidad de la segunda decisión absolutoria, de seguirse el criterio de la aplicación del recurso de queja, habría que concluir que esa decisión es susceptible de ser revisada por vía disciplinaria precisamente porque se da el requisito negativo de la improcedencia de otros recursos y, en ese evento, admitámoslo, estaríamos ante una auténtica sentencia definitiva ya que pone fin a la única instancia que tuvo lugar ante el tribunal de juicio. Sin embargo, esta conclusión, de ser verdadera, trae aparejada consecuencias inaceptables para un sistema de recursos que está construido básicamente para salvaguardar las garantías procesales ${ }^{16}$.

\section{UNA PROPUESTA ACERCA DE LA PROCEDENCIA EXCEPCIONAL DEL RECURSO DE QUEJA EN EL NUEVO PROCEDIMIENTO PENAL}

Lo que va dicho no significa postular la improcedencia del recurso de queja, en términos absolutos, en el nuevo procedimiento penal. Desde luego será procedente cada vez que estemos ante una sentencia definitiva o interlocutoria que ponga término al juicio o haga imposible su continuación y se den los demás requisitos contemplados en el COT.

Obviamente esta afirmación parte del supuesto que no se ha producido una derogación tácita y orgánica del recurso de queja por la entrada en vigor del nuevo sistema procesal penal. Por lo demás, las inconsistencias sistemáticas denunciadas en el apartado anterior se han referido principalmente a la resolución definitiva del conflicto penal y no se puede negar la existencia de algunas decisiones que, dictadas con error manifiesto, pueden ser absolutamente inicuas y deben ser removidas por la única vía que resulta procedente -el recurso de queja- como es el caso de la resolución que declara el abandono de un recurso de nulidad ${ }^{17}$.

Sin embargo, sostener la vigencia del recurso de queja, trae aparejado que decisiones tales como la sentencia de segunda instancia en el procedimiento abreviado y la sentencia que se dicte como consecuencia de la anulación previa de un juicio, harían procedente su revisión disciplinaria. Constituye una excepción explícita la hipótesis en que se haya anulado un juicio que había generado una sentencia absolutoria y, como consecuencia de la anulación, se ha producido una condena, evento en el cual, por disposición del artículo 387 del CPP, inciso segundo, parte final, procede expresamente el recurso de nulidad en favor del imputado cosa que indudablemente excluye el recurso de queja.

16 El carácter de garantía procesal del derecho al recurso aparece de manifiesto en algunos instrumentos internacionales sobre la materia. Así el Artículo $14 \mathrm{~N}^{\circ} 5$ del Pacto Internacional de Derechos Civiles y Políticos señala que "toda persona declarada culpable de un delito tendrá derecho a que el fallo condenatorio y la pena que se le haya impuesto sean sometidos a un tribunal superior, conforme a lo prescrito por la ley". Asimismo el artículo $8 \mathrm{~N}^{\circ} 2$, letra h), sobre Garantías Judiciales, de la Convención Americana sobre Derechos Humanos ("Pacto de San José de Costa Rica") consagra el "derecho (de toda persona) de recurrir del fallo ante juez o tribunal superior". Finalmente no está demás recordar el intenso debate parlamentario surgido en torno a la eliminación del recurso de apelación como recurso ordinario contra la sentencia definitiva y el establecimiento del recurso de nulidad como la vía ordinaria de impugnación del fallo. Tal debate confrontó las diversas posiciones en torno a si tal decisión resultaba o no compatible con los instrumentos internacionales antes citados, enfrentándose principalmente las posiciones de dos académicos procesalistas: Hugo Pereira Anabalón y Raúl Tavolari Oliveros. Lo cierto es que, independiente del modelo que en definitiva se impuso, lo que nunca estuvo en discusión era que los recursos constituían una evidente manifestación del debido proceso y por lo tanto una garantía judicial o un derecho para el imputado. (Ver también nota 21).

17 En reciente fallo de la Corte Suprema, de 23 de julio de 2002, Rol de Ingreso 881-02, se acogió un recurso de queja deducido por la Defensoría Penal Pública, en contra de la resolución que había declarado el abandono de un recurso de nulidad. 
Si bien la procedencia del recurso de queja en los restantes casos aparece, prima facie, como una afirmación formalmente correcta, esta conclusión no se puede llevar al extremo de desconocer los principios y garantías que rigen y fundan el nuevo sistema de enjuiciamiento. Así por ejemplo no parece aceptable, de acuerdo con esos principios y garantías ${ }^{18}$, remover por vía de queja la segunda decisión absolutoria, no obstante que sin ninguna duda es una sentencia definitiva, respecto de la cual no procede recurso alguno, por disposición del artículo 387, inciso segundo, del CPP, es decir, formalmente calza con el requisito negativo de procedencia de un recurso de queja: que la sentencia definitiva o interlocutoria no sea susceptible de recurso alguno.

Ahora bien, haciendo abstracción de los principios y garantías, igualmente, mediante un pequeño énfasis interpretativo, se puede llegar al mismo resultado. Se puede sostener que la decisión pronunciada como consecuencia de la anulación de un juicio no es de aquellas sentencias "no susceptibles de recurso alguno", en lo términos exigidos por el artículo 545 del COT, ya que respecto de ellas procede el recurso de nulidad, aunque sea en una sola hipótesis y sólo a favor del imputado. Para decidir si la sentencia que se pronuncia en el juicio que se celebra como consecuencia de una anulación previa es o no susceptible de recurso hacemos una consideración de ella en abstracto, sin importar la resolución en concreto, de acuerdo a su contenido específico, de condena o absolución ${ }^{19}$.

Además, ante la aparente colisión de normas debe primar aquella especial sobre la general. La declaración explícita contemplada en norma especial -y todavía posterioracerca de la improcedencia de recursos, no puede ceder ante la declaración establecida en una norma general sobre procedencia del recurso de queja. Es decir, por sobre el artículo 545 del COT, en cualquier caso, prima el 387 del CPP, sin que haya operado derogación orgánica tácita, sino porque se ha dictado una norma especial que hace expresa excepción a la que tenía aplicación general.

Queda también por considerar la idea que en los extremos restantes, es decir, la sentencia de segunda instancia en el procedimiento abreviado y la sentencia dictada como consecuencia de la anulación de un juicio que ha producido una segunda o doble decisión condenatoria, la única forma coherente de entender subsistente el recurso de queja es como un medio excepcional que se otorga al imputado agraviado por esa sentencia de término. Esta afirmación fluye de considerar que el derecho al recurso es una garantía reconocida al individuo sometido a persecución penal y, obviamente, no a la persona ficticia encargada de la persecución penal. Esta distinción es lícita por la diferente posición de

\footnotetext{
18 Vid Infra nota 21.

${ }_{19}$ Esta interpretación no es para nada una irreflexiva exégesis del artículo 545 del COT. Es una interpretación sistemática y posible. Resulta obvio que, en general, la procedencia de los recursos debe decidirse de cara a las resoluciones judiciales consideradas en abstracto, a menos que la ley señale una regla expresa en el sentido contrario. Así, en el caso de las sentencias interlocutorias la procedencia de determinados recursos se hace depender de su consideración en concreto, de acuerdo a su contenido, por ejemplo, si pone o no término al juicio o si hace o no imposible su continuación. Si se piensa en la decisión condenatoria que ha sido precedida de una absolución anulada, resulta evidente que su consideración en concreto, sentencia definitiva condenatoria, la hace "no susceptible de recurso alguno" respecto de la parte acusadora y, a pesar de ello, nadie podría sostener que esa consideración en concreto haga procedente el recurso de queja para esa parte, ya que su consideración en abstracto tiene prevista que, al menos en una hipótesis, sea susceptible del recurso de nulidad. De no referirse el artículo 545 del COT de una consideración en abstracto de la susceptibilidad de otros recursos, habría que concluir que en la hipótesis excepcional del inciso segundo, parte final, del artículo 387 del CPP, resultan procedentes dos recursos: el de nulidad a favor del imputado y el de queja a favor de la parte acusadora que no ha obtenido toda su pretensión punitiva. Eso no parece justo ni lógico.
} 
acusador y acusado en el proceso penal, no sólo diametralmente opuesta sino que, principalmente, asimétrica ${ }^{20}$.

Un concepto genuino de recurso como garantía para el imputado, respecto de lo cual seguimos a Julio Maier ${ }^{21}$, debe llevar necesariamente a esta conclusión por difícil que resulte ser comprendida y adoptada en un medio jurídico y cultural que recién está incorporando el concepto de que el sistema de garantías está erigido como un muro de contención frente al ius puniendi2 ${ }^{2}$.

Como que el recurso de queja proviene de las facultades disciplinarias de los tribunales superiores y, especialmente de la Corte Suprema, difícilmente será eliminado ni en su praxis ni en su diseño normativo. De su mantenimiento en la praxis judicial responderemos en gran medida los litigantes. En cuanto a su diseño normativo, compatible con el nuevo sistema procesal penal, no comprendemos su preterición en la discusión parlamentaria.

Admitiendo que es difícil que una intervención legislativa aborde el asunto eliminando el recurso, más vale instar por una regulación normativa que controle sus

20 Como señala Muñoz Conde "es un hecho evidente que las posiciones del acusador y del acusado son diferentes en el proceso penal. Aquél no tiene, por ejemplo, derecho a ser informado de la posición del acusado, y éste sí lo tiene a ser informado de la del acusador. Pero es sobre todo en materia de recursos donde mejor se ve este desequilibrio que siempre se resuelve en beneficio del acusado". En apoyo de esta afirmación Muñoz Conde no sólo se basa en normas de aplicación en Europa sino que también en el Pacto Internacional de Derechos Civiles y Políticos. Francisco Muñoz Conde, La búsqueda de la verdad en el proceso penal, Hammurabi, Buenos Aires, 2000, pág 62.

${ }_{21}$ Nos referimos básicamente a las siguientes propuestas, construidas a partir de las garantías procesales establecidas en la Convención Americana sobre Derechos Humanos o Pacto de San José de Costa Rica (artículo $8, \mathrm{~N}^{\circ} 2$, letra h)) y el Pacto Internacional sobre Derechos Civiles y Políticos (artículo 14, $\mathrm{N}^{\circ}$ 5): a) El recurso como garantía procesal y no como medio de control estatal de los órganos superiores del Estado sobre sus inferiores; b) El recurso contra la sentencia como medio de impugnación unilateral, como derecho exclusivo del condenado a exigir doble conformidad con la condena y c) La condena no recurrida a favor del imputado queda a firme por su solo pronunciamiento y cualquier persecución penal posterior debe ser considerada un bis in idem. Incluso esta última conclusión, que en Chile iría en contra de texto expreso de ley (v.gr. artículo 352 del CPP), tiene un correctivo y es considerar que aún si se concede un recurso al acusador "la condena lograda por él ante un tribunal superior debería permitir todavía un recurso del condenado". Julio Maier, op. Cit, págs. 708,709 y 712.

22 Sin embargo no podemos dejar de citar la labor jurisprudencial de la Corte Suprema en dos importantes precedentes sentados en sendos fallos de veintisiete de marzo de dos mil dos y de $1^{\circ}$ de abril de dos mil dos (disponibles en la página web de la Defensoría Penal Pública: www.defensoriapenal.cl). Estos fallos, sobre recursos de nulidad interpuestos por el Ministerio Público ante la Corte Suprema deducidos con la finalidad de uniformar jurisprudencia sobre la correcta aplicación del artículo 395 del Código Procesal Penal, rechazan la posibilidad de esgrimir garantías constitucionales como herramientas de la persecución penal eficiente, tal como lo sostenía la parte acusadora y recurrente de nulidad que, en virtud del principio de legalidad o reserva, instaba por la aplicación de penas más gravosas que las impuestas en la sentencia de juicio. Estos señeros fallos sientan la siguiente doctrina: "Que el principio de reserva o de legalidad penal, establecido en el artículo $19 \mathrm{~N}^{\circ} 3$ inciso $7^{\circ}$ de la Constitución Política aludido en el recurso, establece que "ningún delito se castigará con otra pena que la que señale una ley promulgada con anterioridad a su perpetración, a menos que una nueva ley favorezca al afectado", lo cual se traduce en lo sustancial, en que sólo la ley puede crear delitos y establecer sus penas, concepto que hay que complementar necesariamente con los principios de la irretroactividad de la ley penal y la tipicidad. A este respecto es bastante dudoso que el Ministerio Público con la intención de sancionar más severamente a un imputado de un delito pueda fundar la nulidad en el principio de reserva constitucional que históricamente se ha establecido para contener el poder del Estado en el ejercicio del ius puniendi y por lo tanto, resultan tales principios baluartes de defensa de personas que, incriminadas puedan resultar condenadas por hechos no sancionados por la ley, no tipificados adecuadamente o no establecidos como delictivos a la época de su comisión y por ello no resulta admisible invocar tales principios para imponer penas mayores a las aplicadas al imputado". 
efectos más perniciosos, contemplando por ejemplo una cláusula expresa de intangibilidad de la decisión jurisdiccional; la expresa formulación de la prohibición de extra petita y de la reformatio in peius; establecer el recurso expresamente en favor del imputado 23 o retomar algunas de las ideas que se discutieron en la tramitación de la Ley $\mathrm{N}^{\circ} 19.374$ como fue, por ejemplo, la propuesta para que la decisión que de oficio adopte el tribunal en uso de sus facultades disciplinarias, si importaba modificación total o parcial de una decisión jurisdiccional, fuera acordado en Tribunal Pleno a requerimiento de su Presidente o de cinco Ministros ${ }^{24}$.

Entre tanto habrá que seguir sosteniendo la improcedencia del recurso de queja cuando no estemos ante resoluciones que genuinamente lo hagan procedente y exigir su aplicación restrictiva para las escasas hipótesis que habrían sobrevivido a la transformación del sistema de enjuiciamiento penal.

\section{MINIMAS CONSIDERACIONES SOBRE UN FALLO DE LA CORTE SUPREMA QUE ACOJE UN RECURSO DE QUEJA DEJANDO SIN EFECTO UNA SENTENCIA DE NULIDAD PARCIALMENTE ABSOLUTORIA 25}

\footnotetext{
${ }^{23} \mathrm{La}$ incorporación de recursos sólo a favor del imputado se contemplaba en el proyecto de la Cámara de Diputados específicamente al contemplarse el recurso extraordinario. Ahora bien, la diferente posición del imputado y del órgano de persecución penal frente a los recursos no sólo viene dado por la adopción de una postura ideológica frente a los fines de proceso penal, sino que también por consideraciones normativas, las que encontramos en los instrumentos internacionales citados, que consagran ciertas garantías procesales, obviamente a favor de los individuos y no de los órganos de persecución. Pero esta diferenciación no es extraña al diseño normativo vigente que contempla la anulación de oficio del fallo, a favor del imputado, tratándose de un motivo absoluto de nulidad (artículo 379, inciso $2^{\circ}$ del CPP), la facultad de recurrir de nulidad, concedida en favor del acusado, en contra de la sentencia condenatoria que se dicte en el segundo juicio anulado (artículo 387, inciso $2^{\circ}$ del CPP) y la facultad de dictar sentencia de reemplazo sólo a favor del imputado (artículo 385 del CPP).

${ }^{24}$ Indicación de la Senadora doña Olga Feliú. Raúl Tavolari Oliveros, Recursos de Casación y Queja, Nuevo régimen, Editorial Jurídica Conosur Ltda.. 1996, pág 26.

25 El fallo de la Corte Suprema es de 10 de Julio de 2002, Rol de Ingreso 1386-02 e incide en la causa RUC 010005195-7, RIT 001-2002 del Tribunal de Juicio Oral de Temuco y Rol No 142-2002 R.P.P. de la Iltma. Corte de Apelaciones de Temuco. Por la sentencia de juicio se condenó a JACC a la pena de quince años y un día de presidio mayor en su grado máximo y accesorias legales, como autor del delito de robo con violación en perjuicio de VRC, perpetrado en esa ciudad el tres de Febrero de dos mil uno. Contra esta sentencia el imputado interpuso ante la Iltma. Corte de Apelaciones de Temuco recurso de nulidad, fundado en la causal contemplada en el artículo 373 letra b) del Código Procesal Penal, esto es, porque en el pronunciamiento de la sentencia se habría hecho una errónea aplicación del derecho que habría influido sustancialmente en lo dispositivo del fallo y también se invoca la causal de motivo absoluto de nulidad del 374 letra e), es decir omisión de requisitos de la sentencia. Conociendo de dicho recurso, la Segunda Sala de la Iltma. Corte de Apelaciones de Temuco, integrada por los Ministros don Héctor Toro Carrasco y don Leopoldo Llanos Sagritá y por el Abogado Integrante don Sergio Fonseca Fernández, declaró, mediante sentencia de fecha dieciséis de abril de dos mil dos, que se hacía lugar al referido recurso de nulidad, tan sólo por la primera de las causales invocadas y dictó, con esa misma fecha, sentencia de reemplazo, en la cual condenó a JACC, solamente como autor del delito de violación previsto y sancionado en el artículo 361 del Código Penal, a la pena de seis años de presidio mayor en su grado mínimo y accesorias correspondientes. En contra de estas últimas sentencias, el Ministerio Público de la Araucanía, interpuso el recurso de queja que fue acogido el 10 de Julio de 2002 por la Corte Suprema dejándose sin efecto las sentencias de nulidad y de reemplazo de fecha dieciséis de febrero de dos mil dos de la Segunda Sala de la Iltma. Corte de Apelaciones de Temuco, y disponiéndose la realización de una nueva vista del recurso de nulidad en que incidían por Tribunal no inhabilitado de la Iltma. Corte de Apelaciones de Temuco.
} 


\section{a) Omisión de pronunciamiento explícito sobre la naturaleza jurídica de la resolución enmendada}

El fallo en comento acoge el recurso de queja en base a dos criterios básicos: 1.Que incurre en falta o abuso grave el tribunal que conociendo de un recurso de nulidad "altera los hechos que fueron determinados por el Tribunal del Juicio Oral" ya que ello "desnaturaliza el sentido del nuevo proceso penal, transformando arbitrariamente la nulidad en una verdadera segunda instancia, ajena al espiritu del referido procedimiento" y 2.- Que la Corte Suprema siempre conserva facultades disciplinarias que le permiten actuar en caso de faltas o abusos graves. Así señala que "esta falta o abuso (grave) es susceptible de ser enmendada mediante el recurso de queja a que se refiere el artículo 545 del Código Orgánico de Tribunales, dado que se la comete en una sentencia que pone término al juicio, sin que nada diga contra ello lo preceptuado en el artículo 387 inciso primero del Código Procesal Penal, puesto que aqui se trata de un recurso que tiene por objeto el ejercicio de la facultad disciplinaria de esta Corte, la cual indudablemente se encuentra siempre vigente también respecto de los tribunales que intervienen en el nuevo procedimiento".

Como se ve no hay un pronunciamiento explícito ya que si bien se tipifica un comportamiento constitutivo de falta o abuso grave, es decir, alterar los hechos fijados por el tribunal de juicio, no hay pronunciamiento explícito sobre una materia esencial para determinar lo que se debatió en el recurso, la naturaleza jurídica de la resolución que resuelve un recurso de nulidad.

Cuando el fallo se refiere a que la sentencia de nulidad y de reemplazo es "una sentencia que pone término al juicio" se ocupa una fórmula imprecisa, que nada nos dice en relación a su naturaleza jurídica y que soslaya el pie forzado que impone la aplicación concatenada de los artículos 158 del CPC y 545 del COT. Por ello creemos ver en el considerando tercero una implícita declaración de que siempre (es decir sea o no procedente las vía de impugnación por la cual se tome conocimiento de la falta o abuso) la Corte podrá hacer uso de sus facultades disciplinarias, en forma independiente de la naturaleza de la resolución recurrida, aún de oficio, ya que reclama para sí "el ejercicio de la facultad disciplinaria" que "indudablemente se encuentra siempre vigente también respecto de los tribunales que intervienen en el nuevo procedimiento".

\section{b) Alteración de los hechos fijados en la instancia como constitutivo de falta o abuso grave}

Tal como hemos dicho se ha tipificado una conducta constitutiva de falta o abuso grave: alterar los hechos fijados por el tribunal de juicio. Esta declaración, en abstracto, nos parece convincente y resulta compatible con los extremos que hemos propuesto y que permitirían la revisión disciplinaria a favor del imputado.

Sin embargo es necesario recordar que este criterio se asemeja mucho al diseño del recurso extraordinario que había incorporado la Cámara de Diputados en el sentido de autorizar la enmienda de la decisión condenatoria del Tribunal Oral que "se apartare manifiesta y arbitrariamente de la prueba rendida en la audiencia". No obstante que se optó en definitiva por eliminar ese recurso, en la iniciativa original siempre se entendió que se trataba de un recurso de competencia propia de las Cortes de Apelaciones ${ }^{26}$.

26 En los antecedentes legislativos consta que "con el establecimiento de aquel recurso extraordinario, se eliminaba la casación por apartamiento de la evidencia, que procedía, precisamente, cuando las conclusiones de becho de la sentencia definitiva 
También viene al caso recordar que cuando se eliminó en el Senado tal recurso se tuvo muy presente que al incorporar el motivo absoluto de nulidad referido a la valoración de los medios de prueba que fundamentaren las conclusiones (artículo 374 letra d) en relación con el artículo 297 ambos del CPP) se recogía igualmente la inquietud que tuvo la Cámara al proponerlo, pero "con mayor propiedad" 27.

En definitiva, resulta clara la voluntad del legislador en el sentido de no otorgar competencia a la Corte Suprema para la revisión de la fijación normada de los hechos ya que tal defecto constituye un motivo absoluto de nulidad y, por lo mismo, típicamente de competencia de las Cortes de Apelaciones.

\section{c) ¿Hubo alteración de los hechos?}

No obstante que pudiéramos inclinarnos a considerar que el criterio de distorsión de los hechos fijados puede ser fuente de mucha injusticia y, por lo mismo, excepcionalmente revisable en sede disciplinaria, nos parece que en la especie no se daba ese supuesto, lo que hacía absolutamente improcedente la revisión del fallo.

Pasemos revista los dos presuntos desvíos de la fijación de los hechos que se reprochan y describen en el considerando cuarto de la sentencia en comento:

1.- En primer lugar se señala que se agregó un hecho nuevo a los que se habían determinado en el juicio. Esta adición se habría producido al afirmar los jueces recurridos que "el sólo hecho del registro de una cartera o mochila, no conlleva necesariamente el ánimo de apropiación, ni representa más que un acto exploratorio o preparatorio". También se produciría al agregar que "este solo hecho, preparatorio de un delito, no es punible, no conduce a un principio de ejecución y, por tanto es ajeno al ámbito penal", para concluir finalmente que "menos puede serlo, cuando del resultado de esa exploración o registro se determina que no existe, como en el caso de autos, una cosa susceptible de ser apropiada."

No puede pasar inadvertido que la consideración del registro de una mochila (elemento fáctico) como acto preparatorio o exploratorio y por consiguiente no punible (calificación jurídica) evidentemente no puede considerarse un alejamiento de los hechos fijados puesto que se trata de una típica decisión dogmática: la delimitación de los actos preparatorios y la tentativa.

Ello es tan cierto que más adelante el fallo no tiene más remedio que estimar esta apreciación dogmática como "inaceptable y no la aprobaría ninguna de las diversas concepciones elaboradas para deslindar los actos preparatorios impunes, de los ejecutivos constitutivos de una tentativa

dictada en el juicio oral fueran arbitrarias por apartarse de modo notorio de la prueba rendida en la audiencia. Se pretendía aligerar asi la carga de trabajo de la Corte Suprema quitándole aquello que es menos trascendente, para que conociera por casación sólo de las grandes cuestiones penales" En cuanto a las motivaciones que tuvo la Cámara para proponer su inclusión en el proyecto es de notar lo siguiente: "se quiso, entonces, que en casos excepcionales, generados por ejemplo por el hecho de que la presión social en un lugar determinado hubiere llevado al tribunal de juicio oral a apreciar abiertamente en forma arbitraria la prueba rendida y, sobre esa base, a dictar sentencia condenatoria en circunstancias que debió absolver, pudiera subsanarse esa injusticia. Y la forma de remediarla no sería anulando el fallo y dictando sentencia de reemplazo, sino ordenado la repetición del juicio oral" (Emilio Pfeffer Urquiaga, Código Procesal Penal anotado y concordado, Ed. Jurídica, pág. 369 y ss.)

${ }^{27}$ Ib. Idem nota 11. 
punible" agregando todavía que "no obstante, por desacertada que sea, esa conclusión fue obtenida por los integrantes del tribunal recurrido en el ejercicio de las facultades interpretativas que el Código Procesal Penal le confiere privativamente; en consecuencia, el haber llegado a ella no se le puede censurar como una falta o abuso y sólo puede contemplárselo como un error infortunado que escapa a las facultades disciplinarias de esta Corte" (considerando sexto)

Subsistiría entonces la adición de la "inexistencia de cosa susceptible de ser apropiada" que se la considera "una afirmación de becho que ba sido adicionada por la sala recurrida ya que en parte alguna de la sentencia de juicio se encontrará semejante acerto el cual ha sido literalmente "inventado" por la sentencia de nulidad".

Esta afirmación resulta muy cuestionable en materia de determinación de la verdad procesal. Es una verdad jurídica afincada que los hechos negativos no pueden ser objeto de prueba, de tal manera que no resultaba posible considerar que la "inexistencia de algo susceptible de ser apropiado" era un hecho no fijado por el tribunal de juicio y, por consiguiente "inventado", ya que la no existencia de algo no podía ser objeto o tema de la fijación de los hechos en la instancia.

Es bien evidente que si existió algo susceptible de ser apropiado (hecho positivo) sólo pudo tenerse procesalmente por cierto en la medida que se hubiere rendido alguna prueba de la existencia de ese algo y, consecuencialmente, se le hubiere tenido por hecho de la causa.

A la inversa, no habiéndose fijado la existencia de algo susceptible de ser apropiado, el juicio negativo expresado por los jueces es absolutamente lícito por el elemental principio de que lo que no se prueba no existe. Así de simple. En otras palabras, el tribunal que aplica el derecho lo aplica a hechos efectivamente establecidos, pero no se necesita una expresa declaración de la no existencia de hechos específicos para razonar sobre la base de esa hipótesis negativa.

Absolutamente todo aquello que no está considerado como hecho procesalmente no existe y, por consiguiente, no requiere de una declaración expresa en la referencia de los hechos fijados.

Tampoco existió en la escena del crimen un instrumento público susceptible de ser adulterado, ni un pasaporte falso susceptible de ser utilizado maliciosamente, ni existió otra víctima, ni tampoco existieron otros malhechores. Como es lógico, por mucho que esos asertos procesales no aparecían por ninguna parte en la sentencia de juicio, estas afirmaciones, de haberse formulado en la sentencia de nulidad, no habrían sido "inventadas" y no habrían constituido apartamiento de los hechos.

Así como era una verdad procesal el mero hecho del registro de una mochila, lo que resultaba ser una falsedad procesal era afirmar la existencia de especies susceptibles de ser sustraídas, sin perjuicio de la duda razonable sobre cualquiera de esos extremos, elemento de convicción este último que quedaba superado por la sola no existencia del hecho ${ }^{28}$.

${ }^{28}$ Como señala Ferrajoli, a propósito de la alternativa entre la verdad formal y la verdad sustancial, al describir la primera nos recuerda que "la verdad perseguida por el modelo formalista como fundamento de una condena es, a su vez, una verdad formal o procesal, alcanzada mediante el respeto a reglas precisas y relativa a los solos hechos y circunstancias perfilados como penalmente relevantes" agregando que sin ser esta la verdad, 
Pero no se puede dejar pasar que esta lícita afirmación era un argumento de refuerzo a una conclusión de evidente connotación jurídica. El acto preparatorio es ajeno al ámbito penal dice el fallo de la Corte de Apelaciones y "menos puede serlo (es decir, a mayor abundamiento, argumento de refuerzo) cuando del resultado de esa exploración o registro se determina que no existe una cosa susceptible de ser apropiada". Entonces este argumento de refuerzo no tenía trascendencia en lo resolutivo -la no punibilidad de los actos calificados jurídicamente como preparatorios- por lo cual se plantea en el fallo un falso dilema, irrelevante para decidir el conflicto, que por el principio de trascendencia no autorizaba a abrogar la decisión revisada disciplinariamente.

2.- En segundo lugar se considera como alteración de los hechos fijados sostener que al registrar la mochila o cartera de la víctima el imputado no haya obrado con dolo de sustraer y con el ánimo apropiatorio (animus rem sibi habendi) indispensables para la tipificación de un robo, no obstante que ambos hechos se encontraban categóricamente establecidos por el Tribunal del Juicio Oral.

Lo primero que surge aquí es que si el dolo fuese en verdad un componente puramente fáctico, con mayor razón debe establecerse con criterios normativos de cognoscibilidad.

Desde luego el dolo no puede aparecer en forma directa de la prueba rendida por su propia naturaleza, inmaterial, según lo destaca acertadamente el fallo de la Corte Suprema.

Si el dolo no se presume (el fallo no insinúa siquiera que el dolo debe presumirse con arreglo al artículo $1^{\circ}$ del Código Penal) entonces debe establecerse mediante algún razonamiento judicial, es decir, su constatación se verifica mediante una deducción normada por el derecho.

Así las cosas, el establecimiento del dolo es de aquellos aspectos típicamente revisables en sede de nulidad, correspondiendo a su establecimiento contrario a derecho un motivo absoluto de nulidad (374 letra e), especialmente en relación con el 297 del $\mathrm{CPP})^{29}$.

\footnotetext{
“es, en suma, una verdad más controlada en cuanto al método de adquisición pero más reducida en cuanto al contenido informativo que cualquier hipotética "verdad sustancial": en el cuádruple sentido de que se circunscribe a las tesis acusatorias formuladas conforme a las leyes, de que debe estar corroborada por pruebas recogidas a través de técnicas normativamente preestablecidas, de que es siempre una verdad solamente probable y opinable y de que en la duda, o a falta de acusación o de pruebas ritualmente formadas, prevalece la presunción de no culpabilidad, o sea, de la falsedad formal o procesal de las hipótesis acusatorias". Asimismo respecto de lo que Ferrajoli denomina cognoscitivismo procesal y estricta jurisdiccionalidad como elementos de la epistemología garantista deriva "un modelo teórico y normativo del proceso penal como proceso de cognición o comprobación, donde la determinación del hecho configurado por la ley como delito tiene el carácter inductivo, que excluye las valoraciones lo más posible y admite sólo, o predominantemente, aserciones o negaciones -de hecho o de derecho- de las que sean predicables la verdad o la falsedad procesal. (Luigi Ferrajoli , Derecho y razón, Editorial Trotta, Quinta Edición, 2001, págs 37 y 45).

29 Se podría afirmar que así como antes la única oportunidad en que la modificación de los hechos resultaba lícita por un tribunal de casación se producía cuando se violaban las denominadas leyes reguladoras de la prueba hoy tal consecuencia procesal se produce precisamente cuando se violan las normas sobre el razonamiento judicial, incluida la ponderación de la prueba de conformidad con el artículo 297.
} 
Entonces, supuesto que el hecho fijado por el tribunal de juicio haya sido "el acusado procedió con dolo" o "el acusado registró la cartera con ánimo de hacer suyas las cosas contenidas en su interior", la pretendida alteración de esos hechos por parte de la Corte de Apelaciones era una opción procesal lícita, precisamente porque la segunda causal de nulidad esgrimida en el recurso, que le daba competencia, era la incorrección en el razonamiento que llevaba al tribunal de juicio a dar por establecidos los elementos típicos del robo, entre ellos, como no, el dolo. Si el recurso no se acogió por tal causal era porque resultaba intrascendente declararla concurrente si los actos preparatorios, aún cometidos con dolo, son igualmente impunes, ya que por su escaso desarrollo impiden considerarlos típicos. En ese entendido toda consideración sobre el dolo resultaba irrelevante ${ }^{30}$.

d) Mínimas consideraciones sobre la determinación del límite entre los actos preparatorios y la tentativa

La Corte Suprema estima que registrar por dos veces la mochila de la víctima, agreguemos, para no contradecir la verdad procesal, de una víctima que en forma absolutamente coetánea a ese registro lo era de un delito de violación en curso, tiene el carácter de acto ejecutivo, citando en apoyo de tal aserto diversas teorías elaboradas para deslindar los actos preparatorios, impunes, de los ejecutivos, constitutivos de una tentativa punible.

De todas las concepciones reseñadas el fallo asume como propia la teoría objetivo-subjetiva sobre la estrecha conexión entre los actos ejecutados conforme al plan del agente y los descritos por el tipo de Welzel y Maurach, la que se considera actualmente dominante en el mejor derecho comparado ${ }^{31}$.

El contenido de esta fórmula, que debe contemplar el plan de autor para dibujar la tentativa, se expresa más o menos de la siguiente manera: "el contenido ejecutivo de los tipos es muy variable y depende de la forma en que el sujeto se haya propuesto consumar. Así lo que determina para cada caso concreto es el plan individual del autor", concepto de acuerdo al cual Welzel la sitúa como teoría objetiva individualizadora. "La tentativa comienza con aquella actividad con la cual el autor, según su plan delictivo, se pone en relación inmediata con la realización del tipo delictivo" (Welzel). Para determinar si la conducta desplegada constituye un "principio de ejecución del crimen o simple delito" el juez necesita saber si el sujeto se proponía cometer una acción punible, cuál era y en qué forma. ${ }^{32}$

Entonces no se entiende cómo el fallo denuncia los resultados absurdos a que puede conducir "un criterio toscamente objetivo sobre la idoneidad de la tentativa" en circunstancias que precisamente lo que se reclamaba para el imputado era una valoración no "toscamente objetiva" sino que una apreciación tanto objetiva como subjetiva de la conducta externa realizada: el registro de una mochila en dos oportunidades. Este acto,

30 El artículo 385 del CPP contempla expresamente la facultad del tribunal de nulidad para que, en caso de acoger el recurso, se pronuncie sólo sobre la causal que le hubiere resultado suficiente.

31 Esta doctrina es aceptada por el Ministro redactor del fallo en su conocida obra por resultar la que "más se conforma con el principio de tipicidad". Este autor denuncia que las concepciones de tendencia marcadamente subjetiva "destruyen la función garantizadora del tipo" y resultan "en consecuencia inaceptables” (Enrique Cury Urzúa, Derecho Penal, Parte General, Tomo II, Segunda Edición, pág 194).

32 Enrique Cury, Ib. Idem. Pág $195 .$. 
apreciado en forma meramente externa aún no servía por si mismo para decidir sobre el principio de ejecución, sin estar precisamente al plan del autor.

Luego si ese plan de autor no se encontraba acreditado sin siquiera asomo de duda razonable, tal acto, insistimos, apreciado en forma meramente externa o toscamente objetiva, podía ser tanto inicio de ejecución de una apropiación, como inicio de ejecución de un apoderamiento para el uso (por ejemplo la búsqueda de un objeto que auxiliara en la reducción o sometimiento de la víctima). Las hipótesis imaginables, sin conocer fehacientemente el plan de autor son innumerables pero, en definitiva, todas posibles. En los hechos fijados en el juicio lo que se evidenció fue la ejecución de un delito de violación y no otro. Es precisamente una consideración toscamente objetiva, sin consideración a un plan de autor acreditado, al menos a nivel de presunción judicial, es decir, de un razonamiento normado, lo que facilita en el fallo que se aprecie como tentativa de apropiación el mero registro de una cartera.

El paradigma propuesto por Dohna, citado con ingenio en el fallo, sirve para confirmar lo señalado. La pretensión de impunidad del que mete la mano a un bolsillo vacío de la víctima, proviene de una consideración puramente objetiva de la tentativa y ello puede ser cierto. Sin embargo esta visión crítica impone la exigencia de una apreciación también subjetiva de ese hecho: el plan de apropiarse de algo en ese bolsillo. Si desconocemos el plan de autor, en ese mismo paradigma, la introducción de la mano en el bolsillo vacío podría no tratarse de un conato de hurto sino que de la consumación de un abuso sexual leve o lisa y llanamente de un acto inocente.

\section{e) Incidencia en las condiciones de independencia personal de los jueces que deberán resolver en forma definitiva el asunto.}

Cabe consignar un último comentario en torno a la decisión de la Corte Suprema que, supuesta una falta o abuso consistente en alterar los hechos, opta por abrogar la sentencia de nulidad y señala los lineamientos con acuerdo a los cuales deberá resolverse el asunto.

Como cuestión previa, entendiendo que la Corte Suprema removió la decisión jurisdiccional usando su potestad disciplinaria genérica, es decir, actuando de oficio, señalemos que ni aún esa potestad permitía la revocación. Por mucho que las potestades disciplinarias encuentran fundamento en el artículo 79, inciso segundo, de la Constitución (en su versión adicionada por reforma constitucional $\mathrm{N}^{\circ} 19.541$, de 22 de diciembre de 1997), ese mismo precepto autoriza a invalidar resoluciones jurisdiccionales, en uso de facultades disciplinarias, tan sólo "en los casos y en la forma que establezca la ley orgánica respectiva", es decir el COT, texto en el cual no aparece una hipótesis como la que se analiza.

Quizás por ello en el fallo queda consignado que aún y cuando usualmente, al acoger un recurso de queja, el tribunal superior corrige las faltas o abusos resolviendo directamente el asunto, en este caso y por tratarse de un asunto sometido al nuevo proceso penal, se estimó que hacerlo así importaría una ingerencia del tribunal de casación en las decisiones de los órganos jurisdiccionales que han intervenido en ese procedimiento, cosa que le parece ajena al espíritu del mencionado sistema. 
En consecuencia y con el objeto de preservar "tanto como le fue posible" los fundamentos y orientaciones de la reforma procesal penal la Corte Suprema se abstiene de dictar una sentencia que sustituyera la removida, pero incurre en el pronunciamiento de una auténtica sentencia de reemplazo virtual, recomendando al inferior jerárquico cómo deberá en definitiva resolver el conflicto aún pendiente.

Esta ingerencia en verdad no pareciera avenirse con la regla contemplada en el artículo $8^{\circ}$ del Código Orgánico de Tribunales que consagra el principio de la inavocabilidad intraorgánica, toda vez que, al quedar sin efecto lo resuelto por la respectiva Corte de Apelaciones, estamos en presencia de una causa o negocio pendiente ante otro tribunal distinto de la Corte Suprema.

Entonces, con el fallo virtual del conflicto, la resolución del asunto de fondo quedó atada con un "nudo gordiano". Por una parte, si el inferior jerárquico falla de acuerdo a la recomendación ello generará una seria sospecha de la independencia personal ${ }^{33}$ de los jueces que la emitan, por la vehemente recomendación proveniente del tribunal que se encuentra en la cúspide de la pirámide, según usualmente se grafica la estructura orgánica del Poder Judicial ${ }^{34}$. Por la otra, si los jueces se apartan de la recomendación queda la duda si la parte acusadora estará nuevamente legitimada para obrar alzándose disciplinariamente $y$, en definitiva, generando un inaceptable regressus in infinitum.

${ }_{33}$ Nos referimos a la independencia personal de los jueces como una manifestación de la universal garantía del derecho al juez independiente, según es expuesta por Alberto Binder en los siguientes términos que : "Es el juez, personalmente, con nombre y apellido, quien no está subordinado a ninguna instancia de poder. No está subordinado al Poder Ejecutivo, ni al Poder Legislativo, pero tampoco -y esto merece ser subrayado- está subordinado a ninguna instancia de poder interna al Poder Judicial”. Más explícito aún, en torno al punto que estamos tratando: "Los llamados "jueces superiores", que son aquellos que conocen sobre algún recurso, o los jueces de la Corte Suprema, no tienen poder sobre el juez ordinario. No podrían, en modo alguno, darle indicaciones o influir sobre él para que decida en uno u otro sentido". Alberto M. Binder, Introducción al derecho procesal, Ad-Hoc, Buenos Aires, segunda edición, 1999, págs. 149 y 150. Esta concepción es explícitamente recogida en Chile por Julián López Masle entendiendo que resulta "consistente con una lectura cuidadosa de las convenciones internacionales de derechos humanos que no hacen referencia al derecho a ser juzgado por un Poder Judicial independiente, sino por un juez independiente, lo que tiene claramente una connotación personal”. María Inés Horvitz Lennon y Julián López Masle, Derecho Procesal Penal Chileno, Tomo I, Ed. Jurídica, 2002, pág 54.

${ }^{34}$ Confiamos en la independencia con la cual, en los hechos, actúan los tribunales, sin embargo, extrapolando los criterios sentados por el Tribunal Europeo de Derechos Humanos, al definir la garantía del juez imparcial, podríamos señalar que los jueces no sólo deben ser independientes sino que también deben parecerlo. (Ver Horvitz y López, Ib. Idem. Pág. 55. Ver Vincent Berger, Jurisprudence de la Cour Européenne des Droits de l'Homme, Sirey Ed., 2000, casos »Piersack c. Bélgica" y «Hauschildt c. Dinamarca» y caso «Procola c. Luxemburgo"). También en relación con la garantía del juez independiente el TEDH ha sentado el criterio que "aún las apariencias pueden tener importancia". (Ver V. Berger, Ib. Idem, casos "Belilos c. Suiza" y "Sramek c. Austria", págs 166 y 179). Sólo así se rompe con una falacia normativista que no considera las apariencias, las que muchas veces pueden generar al menos sospecha de falta de independencia. Bajo la consigna de la destrucción de una falacia normativista -aquella expresada en el Mensaje del antiguo Código de Procedimiento Penal de que "el juez honrado trabajará por no dejarse llevar por meras impresiones"- se abandonó el sistema inquisitivo en Chile. Nadie dudaba de la honradez con que los jueces actuaban. Aún así, durante más de un siglo, no parecieron lo suficientemente imparciales. 